\title{
Metabolomic Comparison and Assessment of Co-Cultivation and a Heat-Killed "Inducer" Strategy in Activation of Cryptic Biosynthetic Pathways
}

\author{
Libang Liang, ${ }^{\dagger}$ Guanqiao Wang, ${ }^{\dagger}$ Bradley Haltli, ${ }^{\dagger, \wedge}$ Douglas H. Marchbank, ${ }^{\dagger, \wedge}$ Henrik \\ Stryhn, ${ }^{\S}$ Hebelin Correa,` Russell G. Kerr ${ }^{\dagger},^{\star}, \wedge$ \\ ${ }^{\dagger}$ Department of Chemistry, University of Prince Edward Island, Charlottetown C1A 4P3, Canada \\ ¿Departments of Biomedical Sciences ${ }^{\S}$ Health Management, Atlantic Veterinary College, University of \\ Prince Edward Island, Charlottetown C1A 4P3, Canada \\ ${ }^{\wedge}$ Nautilus Biosciences Croda, Charlottetown C1A 4P3, Canada
}




\section{Table of Contents}

Figure S1. UHPLC-HRESIMS analysis of inducer cultures before and after autoclaving (S3)

Figure S2. Score plots from principle component analysis (PCA) of metabolomics profiles by treatment (S4)

Figure S3. ${ }^{1} \mathrm{H}$ NMR $(400 \mathrm{MHz})$ data of 1, 92\% purity $\left(\mathrm{CD}_{3} \mathrm{CN}\right)(\mathrm{S} 5)$

Figure S4. ${ }^{13} \mathrm{C}$ DEPTQ135 NMR (100 MHz) data of $1\left(\mathrm{CD}_{3} \mathrm{CN}\right)(\mathrm{S} 6)$

Figure S5. COSY NMR (400 MHz) data of $1\left(\mathrm{CD}_{3} \mathrm{CN}\right)(\mathrm{S} 7)$

Figure S6. ${ }^{1} \mathrm{H}-{ }^{13} \mathrm{C}$ HSQC NMR data $(400 \mathrm{MHz} / 100 \mathrm{MHz})$ of $\mathbf{1}\left(\mathrm{CD}_{3} \mathrm{CN}\right)(\mathrm{S} 8)$

Figure S7. ${ }^{1} \mathrm{H}-{ }^{13} \mathrm{C}$ HMBC NMR data $(400 \mathrm{MHz} / 100 \mathrm{MHz})$ of 1, CNST13(J) $=10 \mathrm{~Hz}\left(\mathrm{CD}_{3} \mathrm{CN}\right)(\mathrm{S} 9)$

Figure S8. ${ }^{1} \mathrm{H}^{-15} \mathrm{~N}$ HSQC NMR data $(400 \mathrm{MHz} / 40 \mathrm{MHz})$ of $1\left(\mathrm{CD}_{3} \mathrm{CN}\right)(\mathrm{S} 10)$

Figure S9. Overlay of ${ }^{1} \mathrm{H}$ NMR (400 MHz) spectra of natural (A) and synthetic (B) and ${ }^{13} \mathrm{C}$ DEPTQ135 NMR (100 MHz) spectra of natural (C) and synthetic (D) versions of 1 in $\mathrm{CD}_{3} \mathrm{CN}$ (S11)

Figure S10. UHPLC-HRESIMS analysis of natural product (A), synthetic product (B), and 1:1 coinjection product $(\mathrm{C})$ of $\mathbf{1}$. The extracted ion chromatogram monitoring ions with $\mathrm{m} / \mathrm{z}$ at 211.0714 (S12)

Figure S11. UHPLC-HRESIMS analysis of Streptomyces sp. RKND-216 fermentation extracts prepared in $\mathrm{MeOH}(\mathrm{A})$ and $\mathrm{ACN}(\mathrm{B})(\mathrm{S} 13)$

Figure S12. FTIR spectrum of 1 measured in $\mathrm{MeOH}$ (S14)

Figure S13. Tandem mass spectra of 1 (S15)

Figure S14. ${ }^{1} \mathrm{H}$ NMR $(600 \mathrm{MHz})$ data of 5, 98\% purity (DMSO- $\left.d_{6}\right)(\mathrm{S} 16)$

Figure S15. COSY NMR (600 MHz) data of 5 (DMSO- $\left.d_{6}\right)(\mathrm{S} 17)$

Figure S16. TOCSY NMR (600 MHz) data of $5\left(\mathrm{DMSO}^{-} d_{6}\right)(\mathrm{S} 18)$

Figure S17. ${ }^{1} \mathrm{H}-{ }^{13} \mathrm{C}$ HMBC NMR (600 MHz / $\left.125 \mathrm{MHz}\right)$ data of 5, CNST13(J) = $5 \mathrm{~Hz}\left(\mathrm{DMSO}-d_{6}\right)(\mathrm{S} 19)$

Figure S18. ${ }^{1} \mathrm{H}-{ }^{13} \mathrm{C}$ HMBC NMR (600 MHz / $\left.125 \mathrm{MHz}\right)$ data of 5, CNST13(J) $=3 \mathrm{~Hz}\left(\mathrm{DMSO}-d_{6}\right)(\mathrm{S} 20)$

Figure S19. ${ }^{1} \mathrm{H}-{ }^{13} \mathrm{C}$ HSQC NMR $(600 \mathrm{MHz} / 125 \mathrm{MHz})$ data of 5 (DMSO- $\left.d_{6}\right)(\mathrm{S} 21)$

Figure S20. ${ }^{13} \mathrm{C}$ DEPTQ135 NMR $(125 \mathrm{MHz})$ data of 5 (DMSO- $\left.d_{6}\right)(\mathrm{S} 22)$

Figure S21. HRMS analysis of reaction product $7\left(\mathrm{C}_{23} \mathrm{H}_{22} \mathrm{~N}_{3}\right.$, calcd 340.1808$)(\mathrm{S} 23)$

Figure S22. FTIR spectrum of compound 5 (S24) 


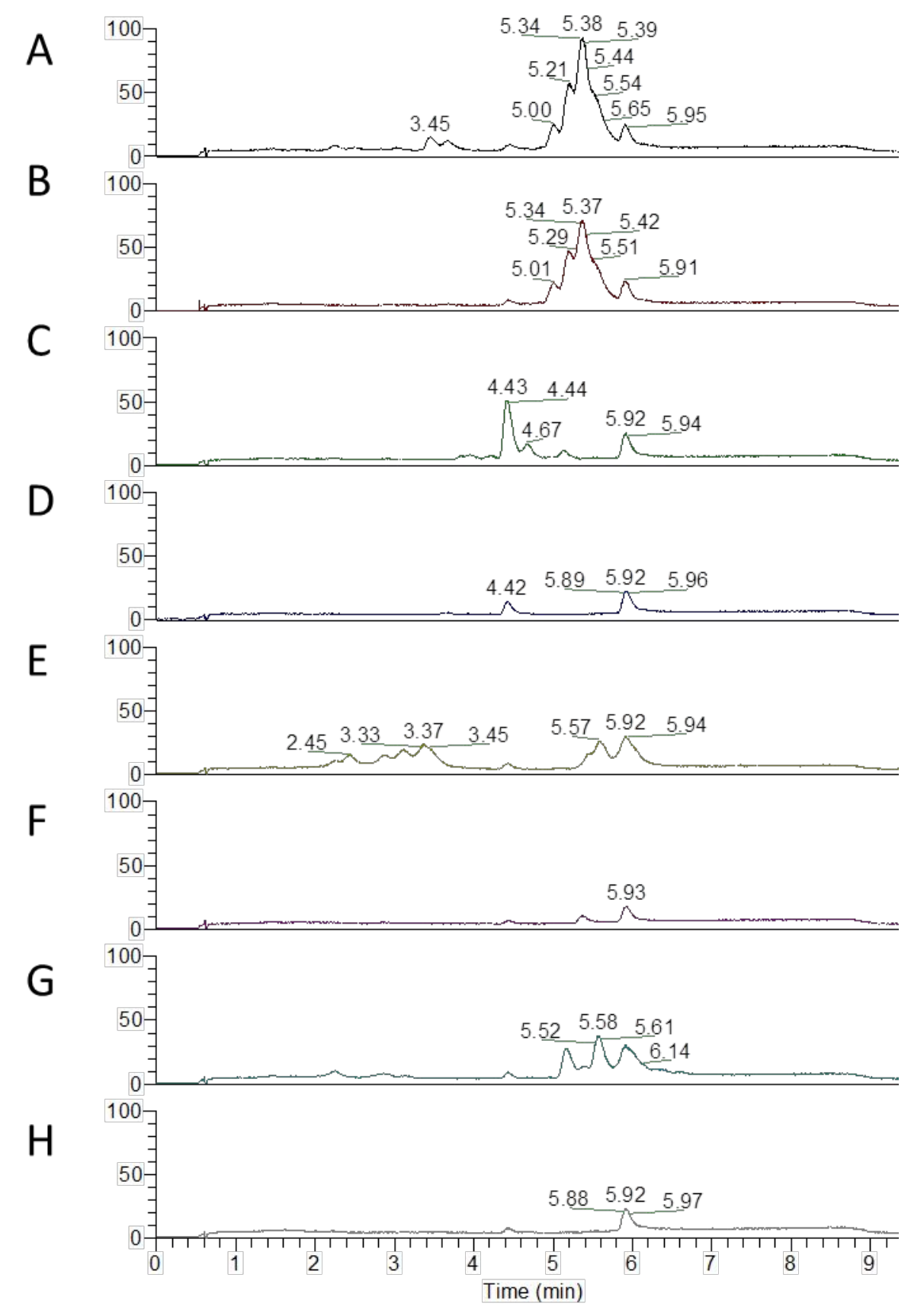

Figure S1. UHPLC-HRESIMS analysis of inducer cultures before and after autoclaving. Live (A) are and autoclaved (B) B. subtilis extracts; live (C) and autoclaved (D) Halomonas sp.

RKEM-883 extracts; live (E) and autoclaved (F) Alteromonas sp. RKMC-009 extracts; are live $(\mathrm{G})$ and autoclaved $(\mathrm{H})$ M. smegmatis. These chromatograms are representative of six replicates. In (A) and (B), the peak at 5.01, 5.20, and 5.36 min correspond to surfactin A $(\mathrm{m} / \mathrm{z} 1008.6666$ $[\mathrm{M}+\mathrm{H}]^{+}$, calcd 1008.6597), surfactin B $\left(\mathrm{m} / z 1022.6819[\mathrm{M}+\mathrm{H}]^{+}\right.$, calcd 1022.6753) and surfactin $\mathrm{C}\left(\mathrm{m} / z\right.$ 1036.6959 $[\mathrm{M}+\mathrm{H}]^{+}$, calcd 1036.6910). 

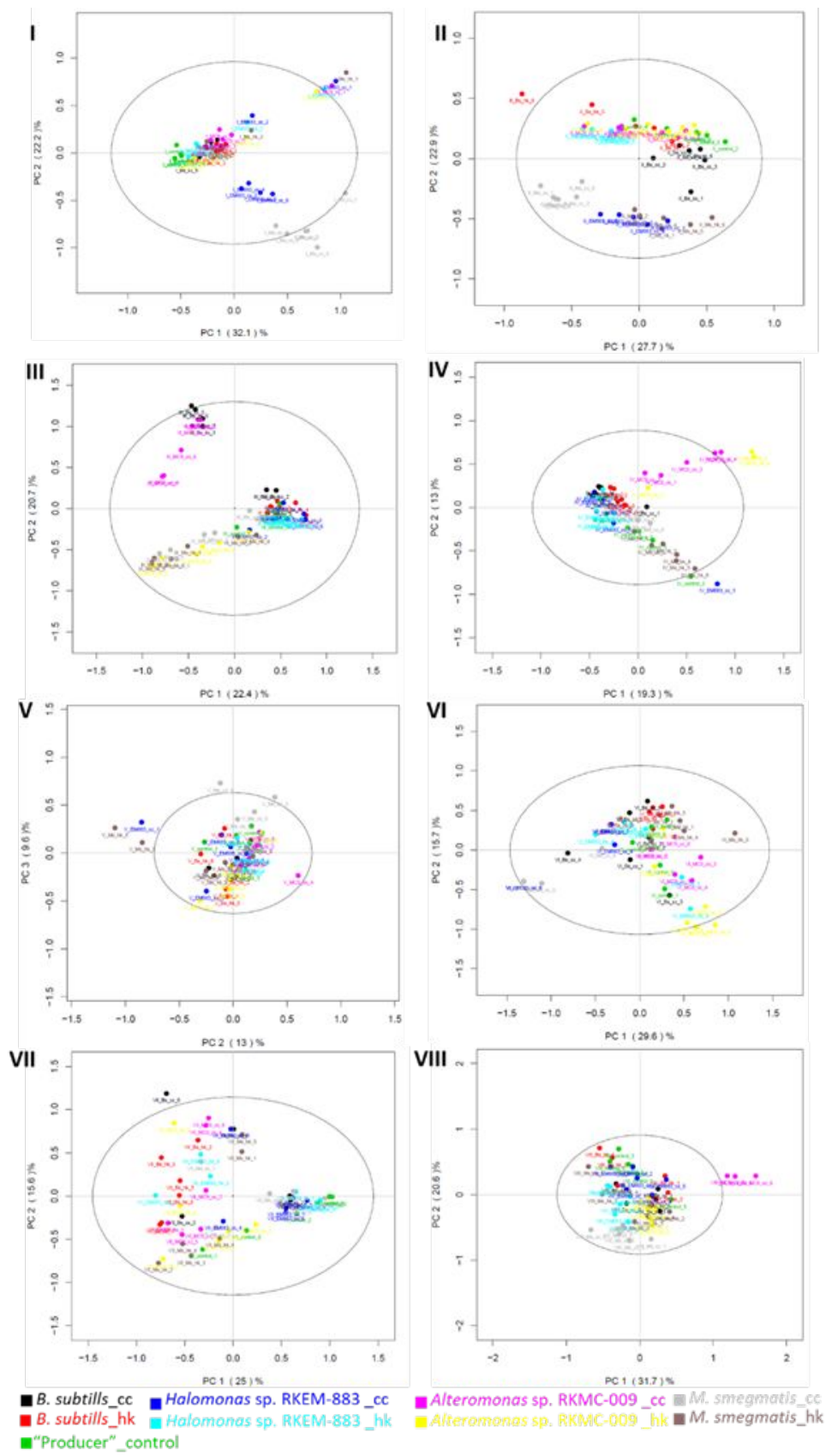

Figure S2. Score plots from principle component analysis (PCA) of metabolomics profiles by treatment. The labels from I to VIII correspond to producer I to producer VIII. The metabolic profiles from different treatments were color-coded; six replicates from the same treatment were represented by six dots in the same color. All the score plots show PC1 and PC2. 


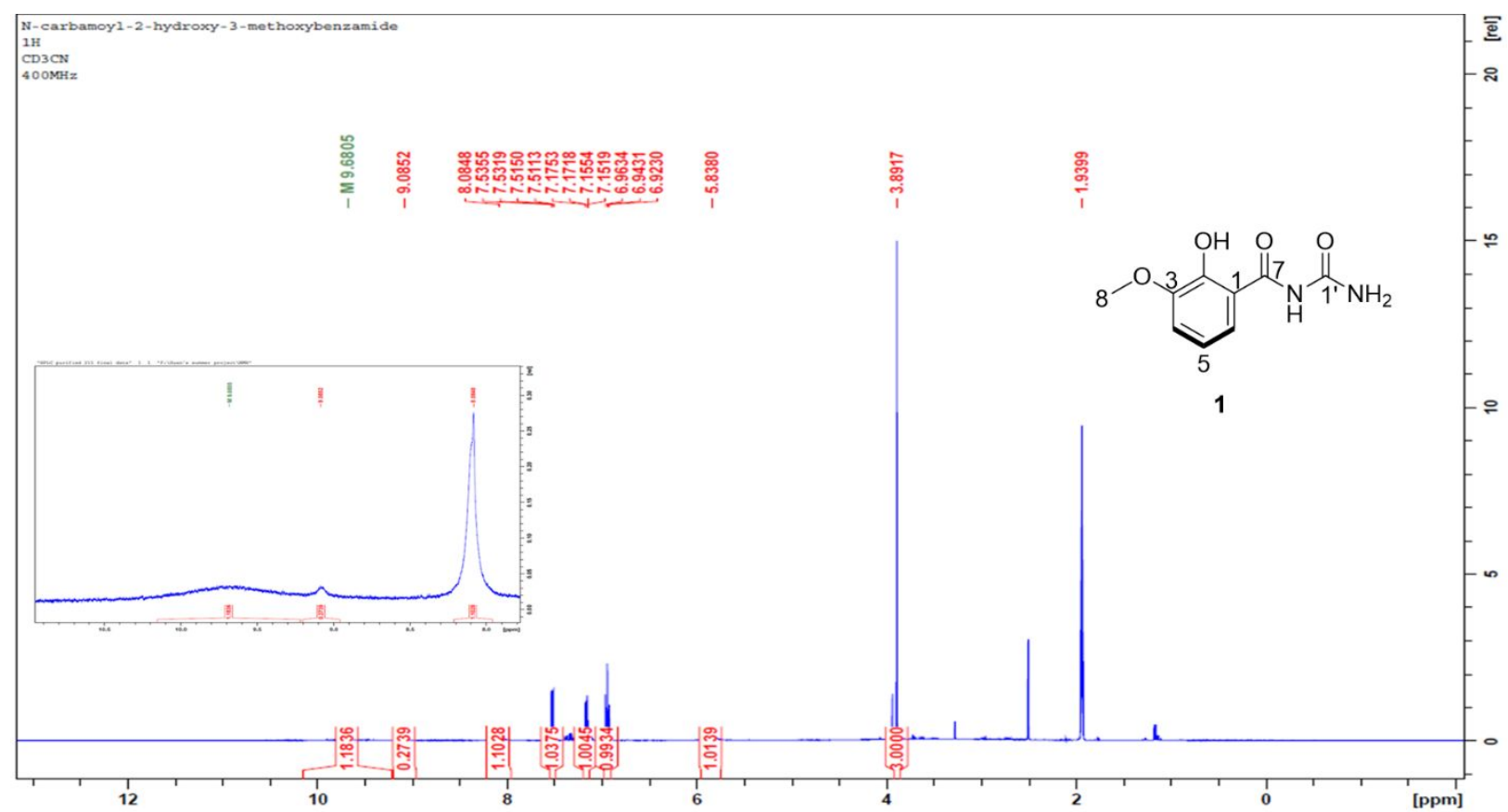

Figure S3. ${ }^{1} \mathrm{H}$ NMR $(400 \mathrm{MHz})$ data of $1,92 \%$ purity $\left(\mathrm{CD}_{3} \mathrm{CN}\right)$. 


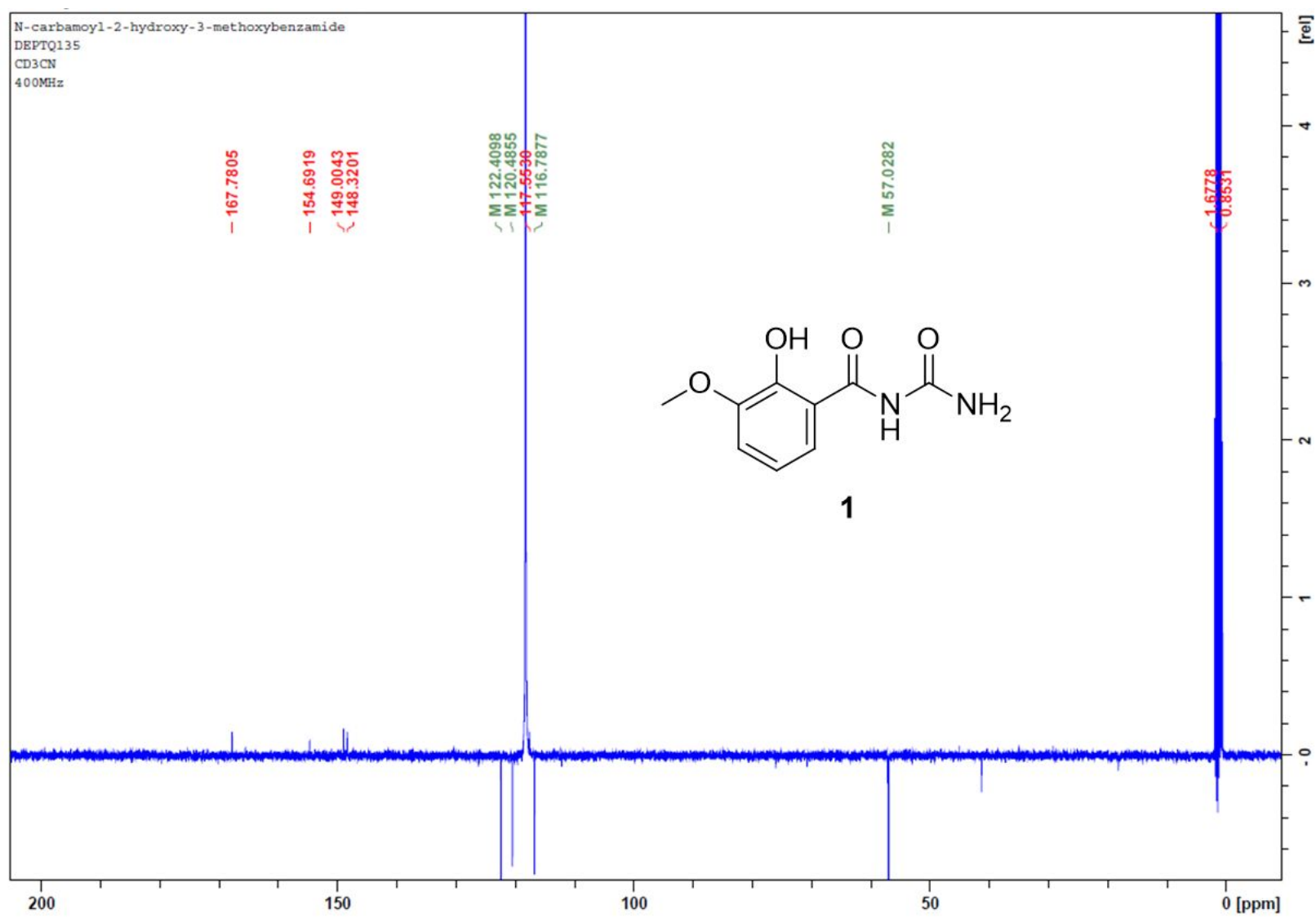

Figure S4. ${ }^{13} \mathrm{C}$ DEPTQ135 NMR $(100 \mathrm{MHz})$ data of $1\left(\mathrm{CD}_{3} \mathrm{CN}\right)$. 


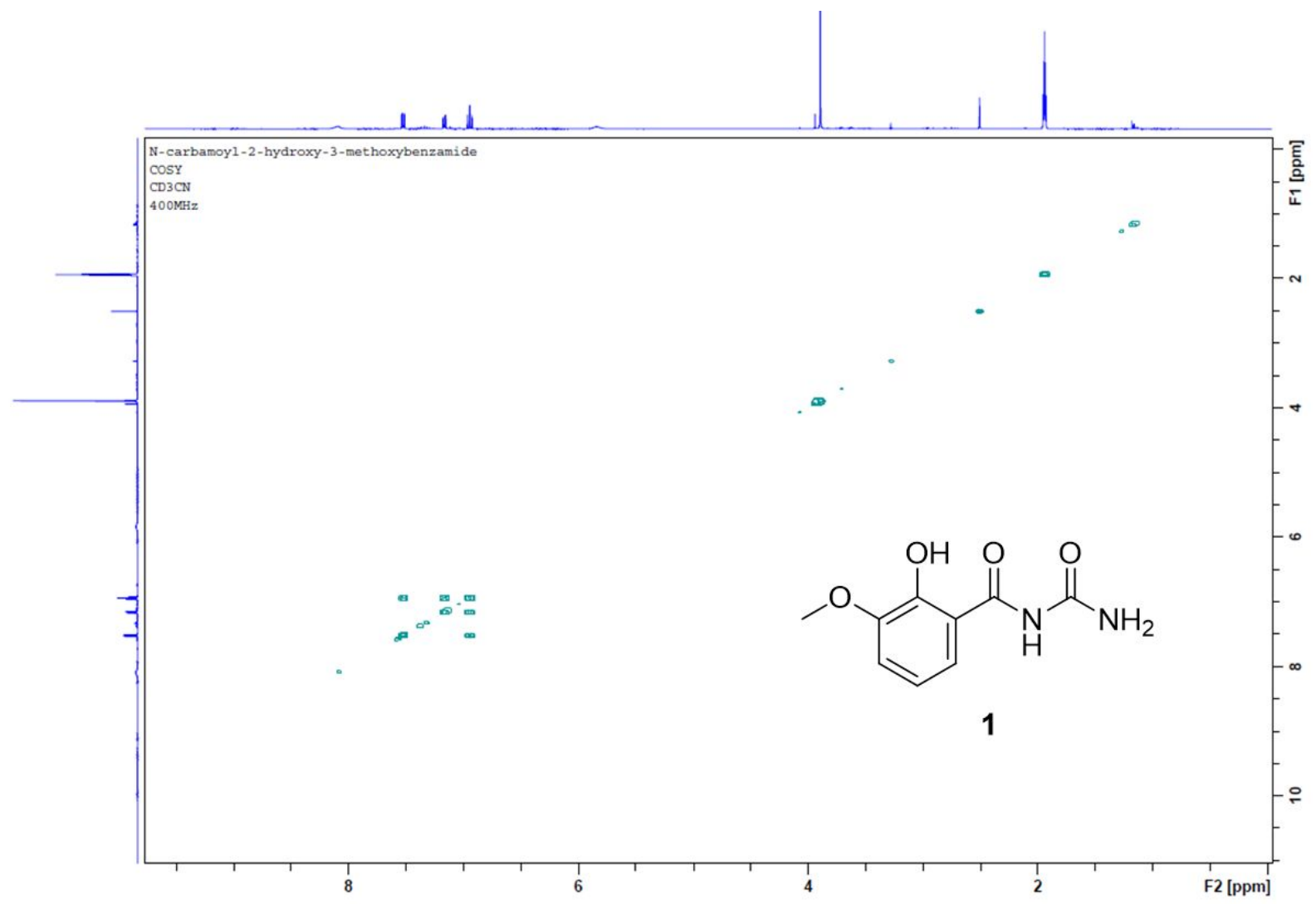

Figure S5. COSY NMR (400 MHz) data of $1\left(\mathrm{CD}_{3} \mathrm{CN}\right)$. 


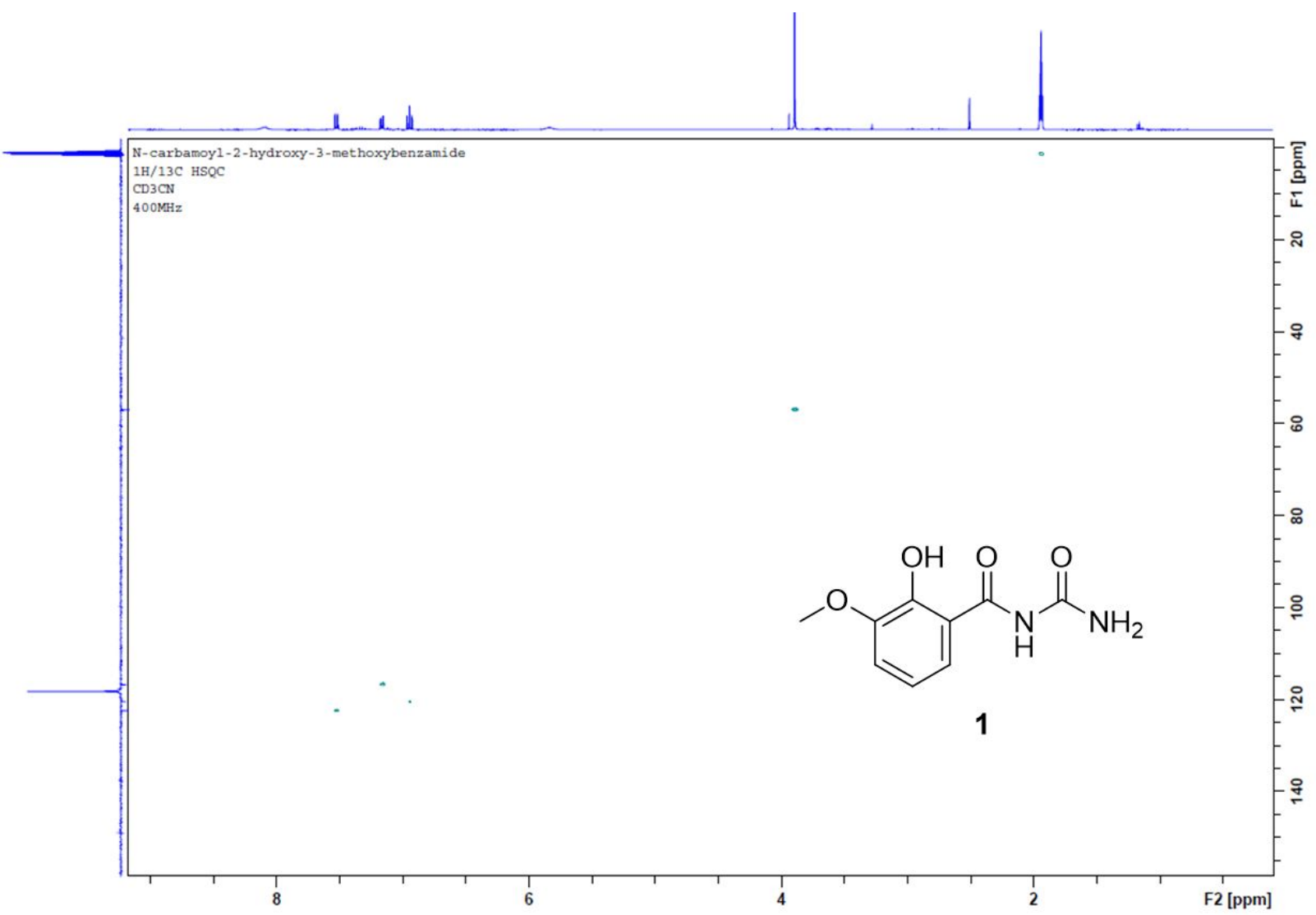

Figure S6. ${ }^{1} \mathrm{H}-{ }^{13} \mathrm{C}$ HSQC NMR data $(400 \mathrm{MHz} / 100 \mathrm{MHz})$ of $1\left(\mathrm{CD}_{3} \mathrm{CN}\right)$. 


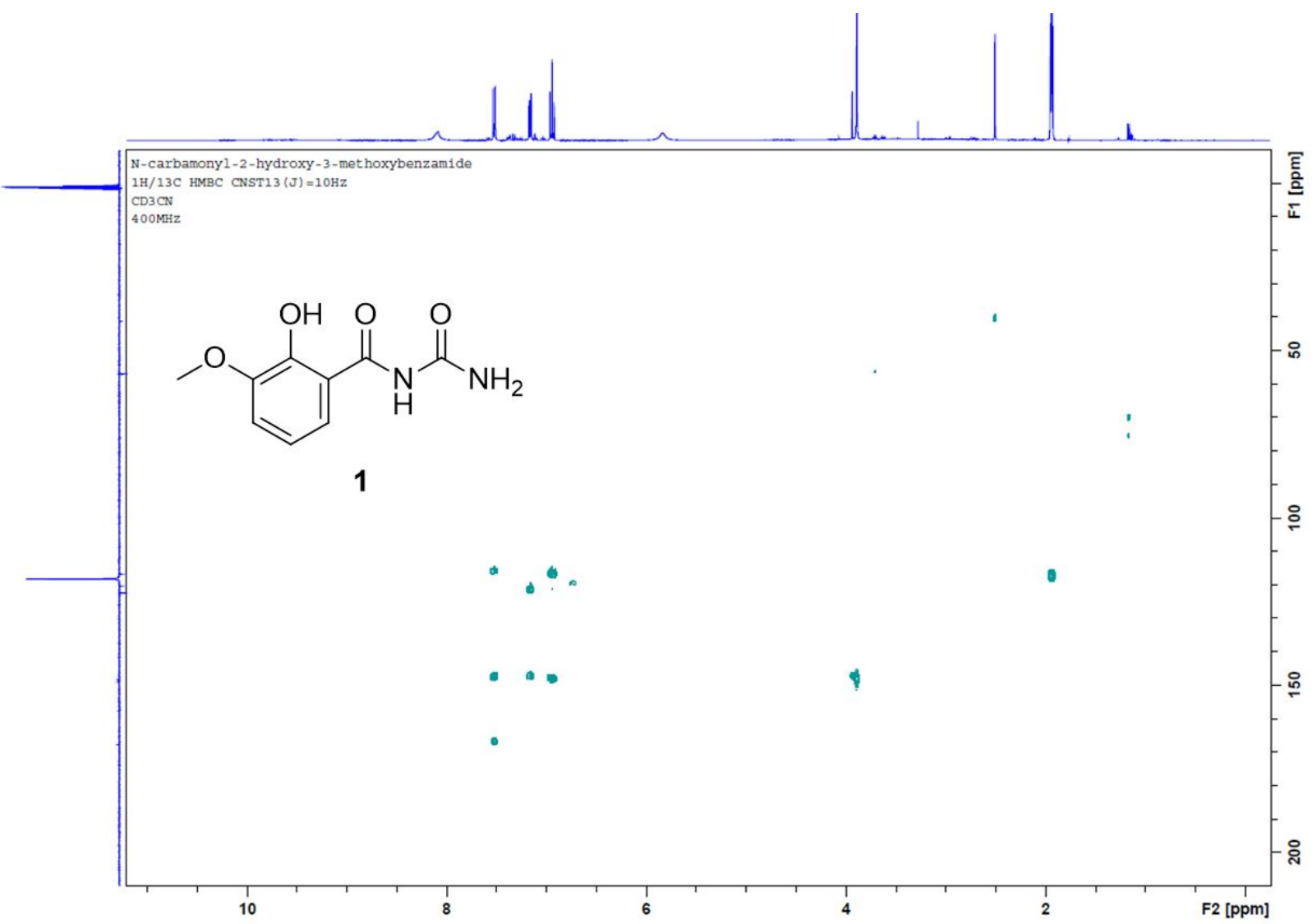

Figure S7. ${ }^{1} \mathrm{H}-{ }^{13} \mathrm{C}$ HMBC NMR data $(400 \mathrm{MHz} / 100 \mathrm{MHz})$ of $\mathbf{1}, \mathrm{CNST} 13(\mathrm{~J})=10 \mathrm{~Hz}$ $\left(\mathrm{CD}_{3} \mathrm{CN}\right)$. 


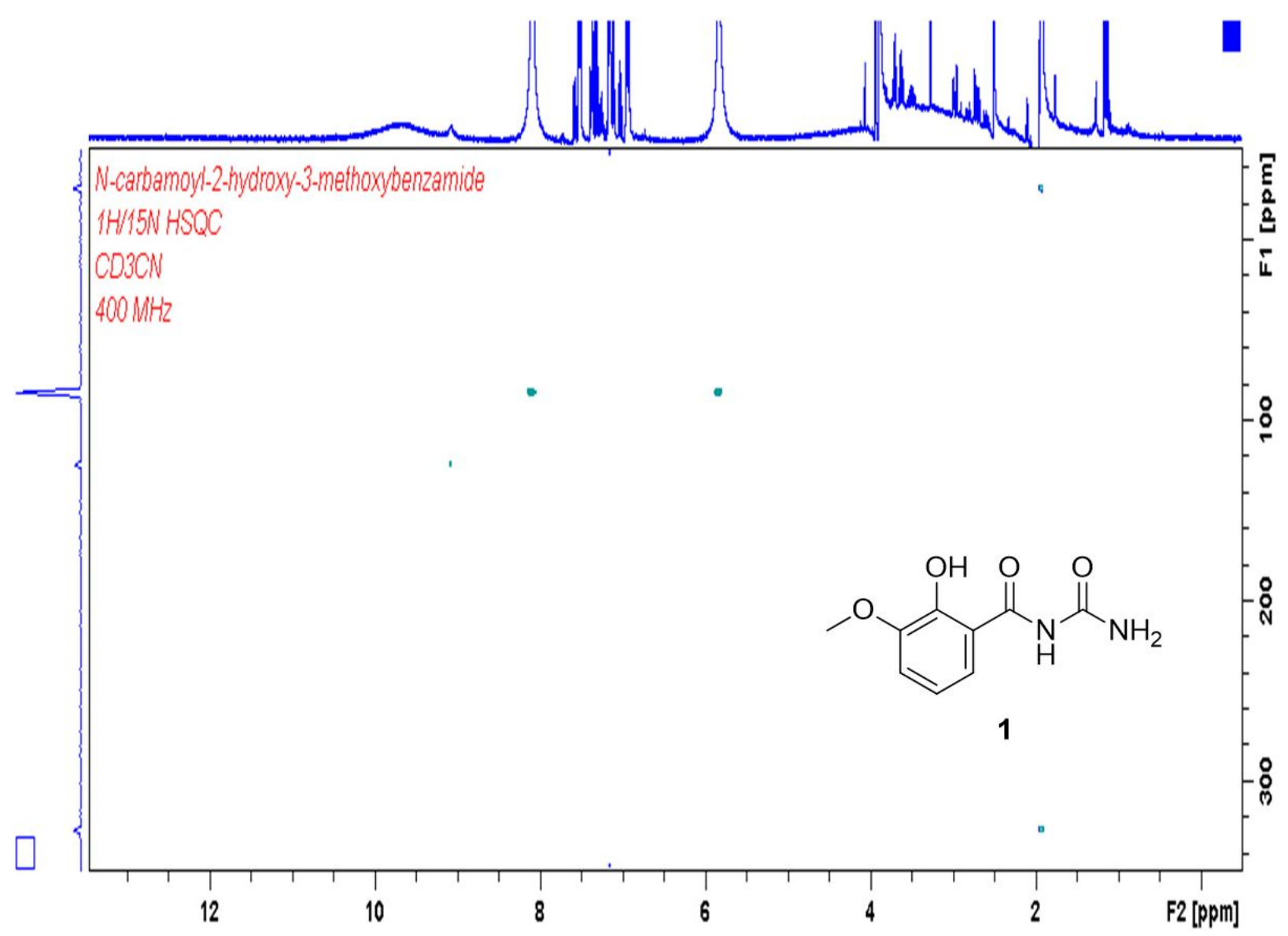

Figure S8. ${ }^{1} \mathrm{H}^{15} \mathrm{~N}$ HSQC NMR data $(400 \mathrm{MHz} / 40 \mathrm{MHz})$ of $1\left(\mathrm{CD}_{3} \mathrm{CN}\right)$. 


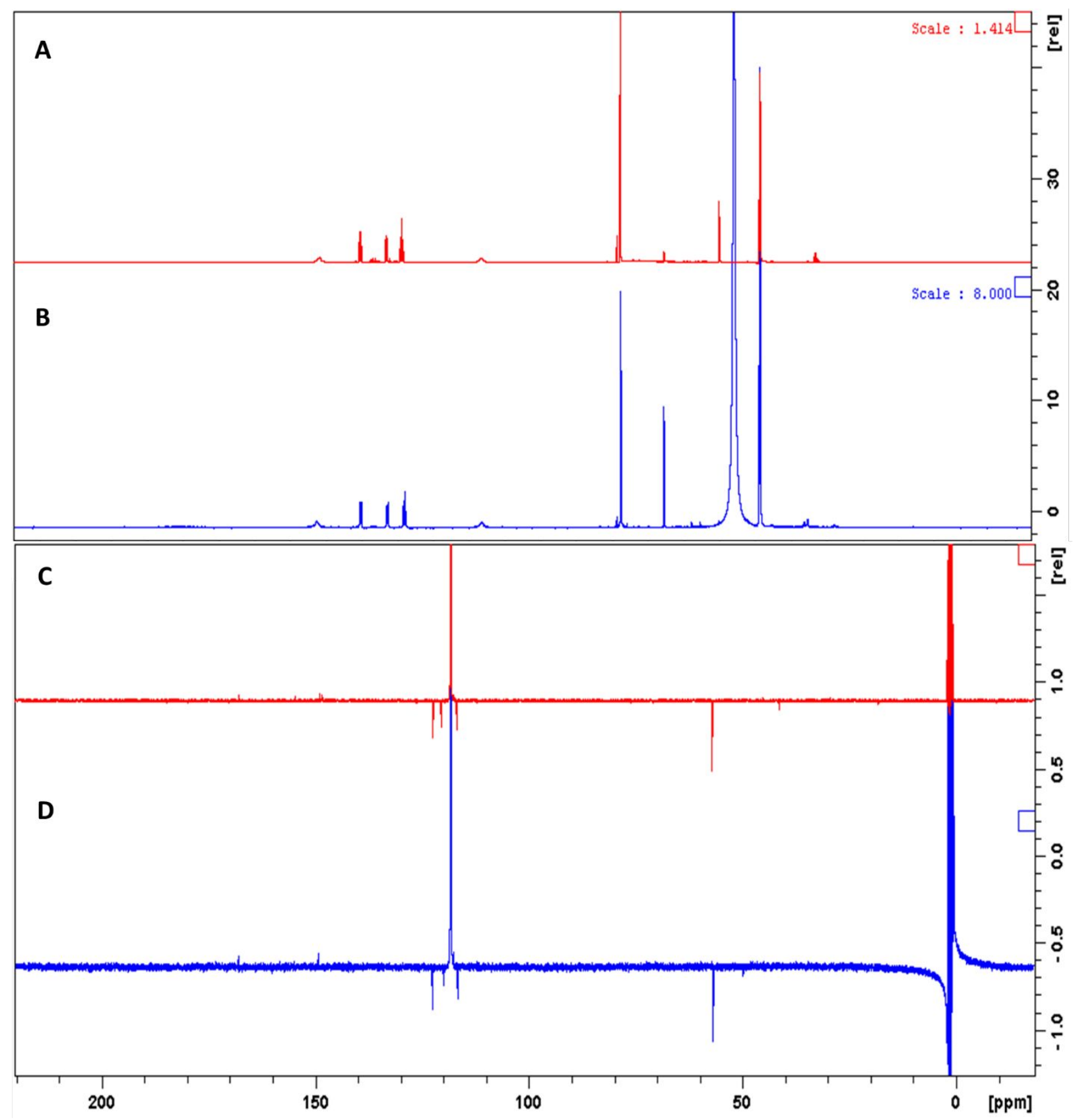

Figure S9. Overlay of ${ }^{1} \mathrm{H}$ NMR $(400 \mathrm{MHz})$ spectra of natural (A) and synthetic (B) and ${ }^{13} \mathrm{C}$ DEPTQ135 NMR (100 MHz) spectra of natural (C) and synthetic (D) versions of 1 in $\mathrm{CD}_{3} \mathrm{CN}$. 


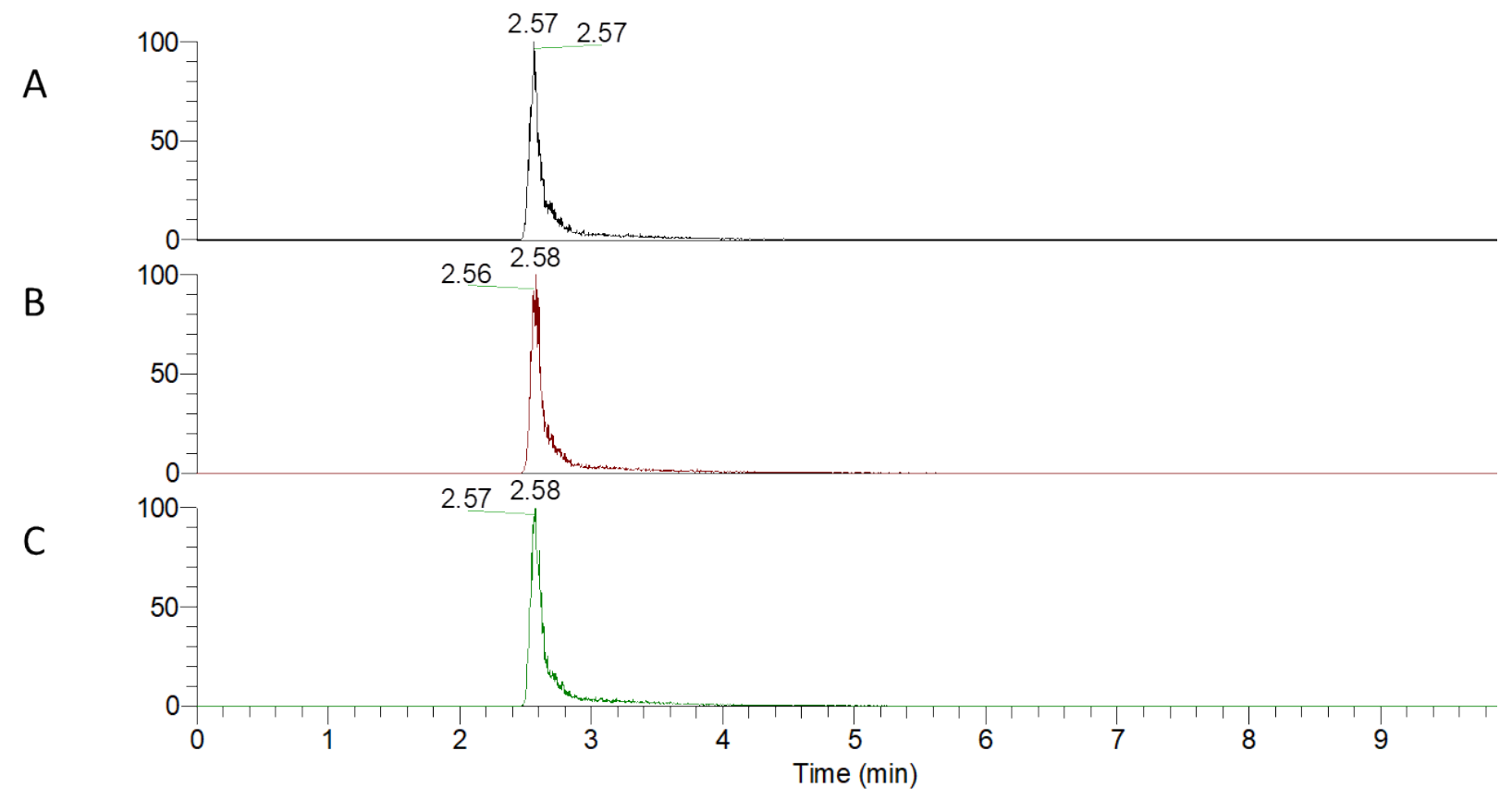

Figure S10. UHPLC-HRESIMS analysis of natural product (A), synthetic product (B), and 1:1 co-injection product (C) of $\mathbf{1}$. The extracted ion chromatogram monitoring ions with $\mathrm{m} / \mathrm{z}$ at 211.0714 . 


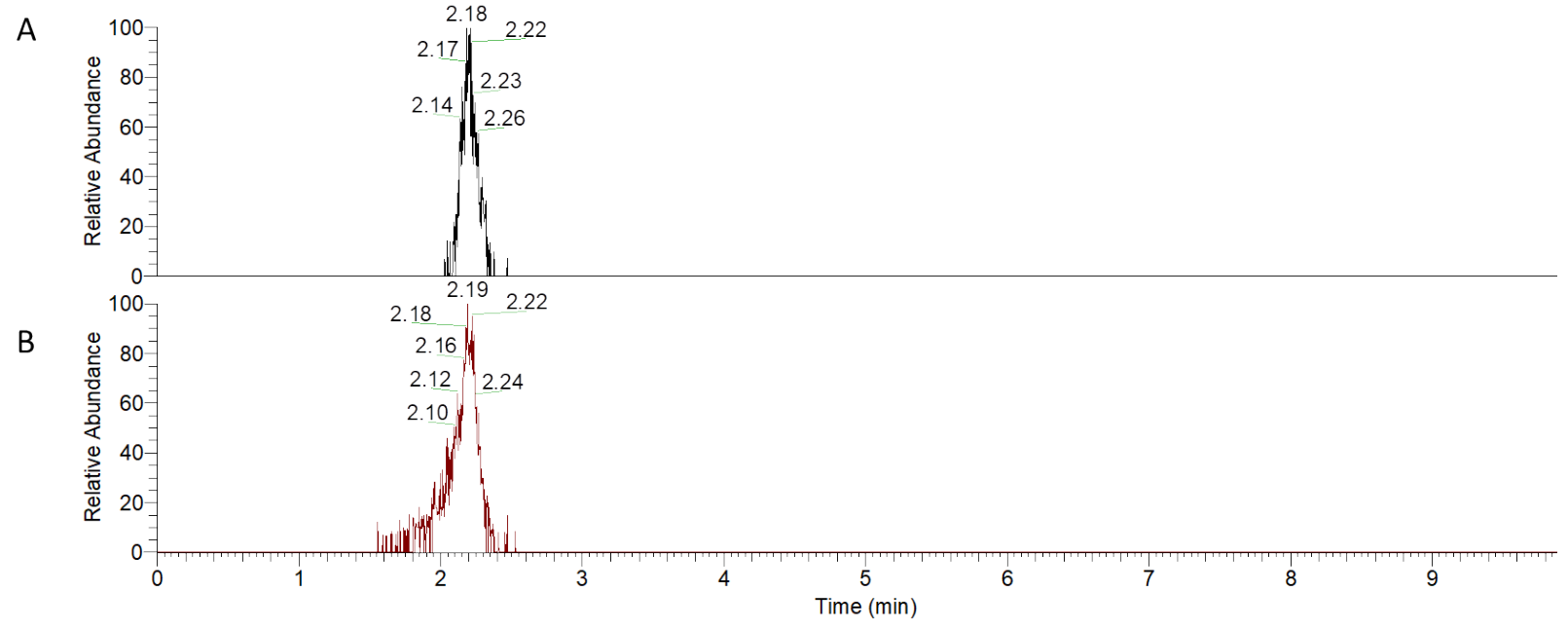

Figure S11. UHPLC-HRESIMS analysis of Streptomyces sp. RKND-216 fermentation extracts prepared in $\mathrm{MeOH}(\mathrm{A})$ and $\mathrm{ACN}(\mathrm{B})$. The extracted ion chromatogram monitoring ions with $\mathrm{m} / \mathrm{z}$ at 211.0714. The LC solvents were $\mathrm{ACN}$ and $\mathrm{H}_{2} \mathrm{O}$ with $0.1 \%$ FA described in the Experimental Section. 


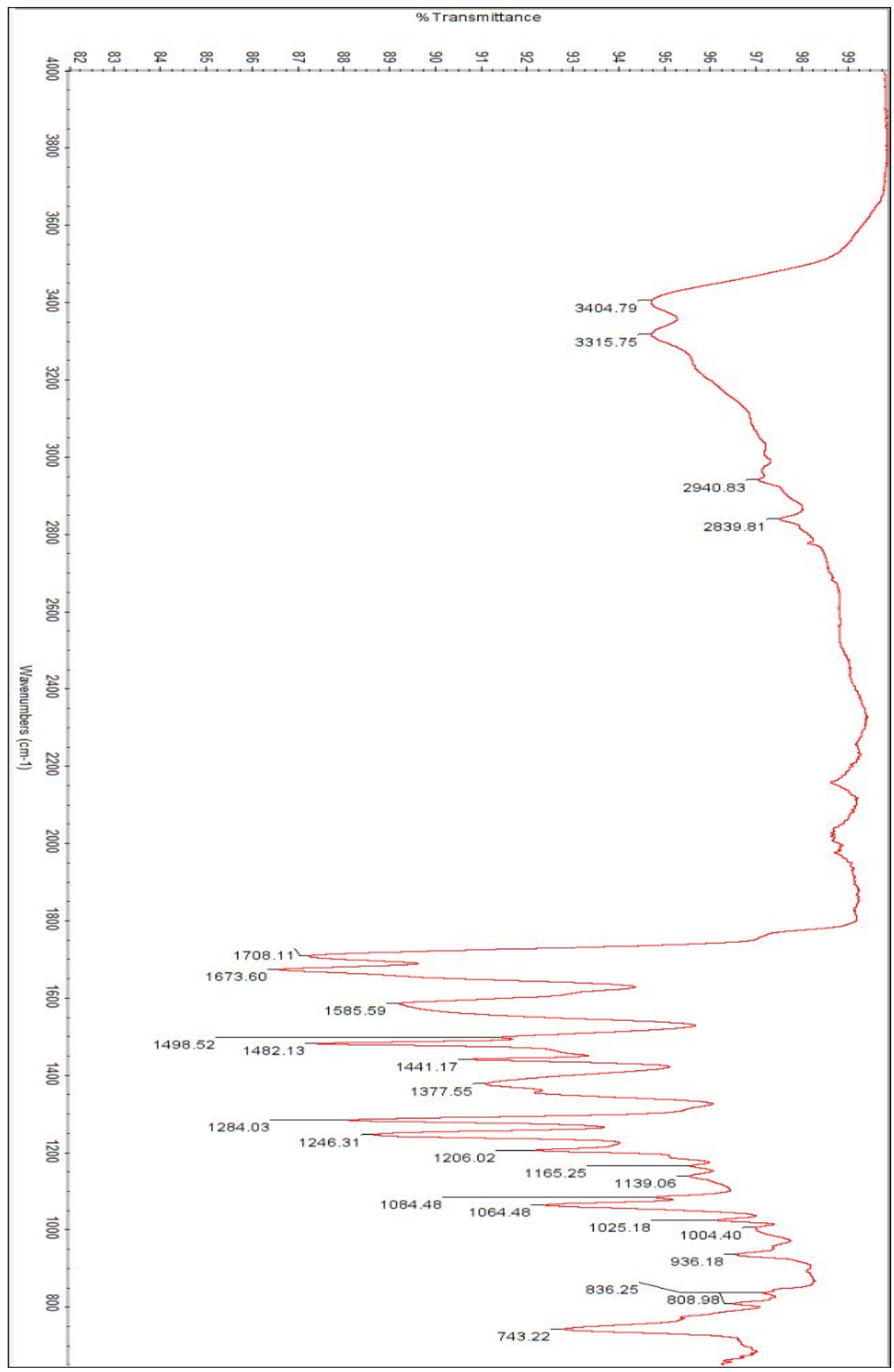

Figure S12. FTIR spectrum of 1 measured in $\mathrm{MeOH}$. 
A

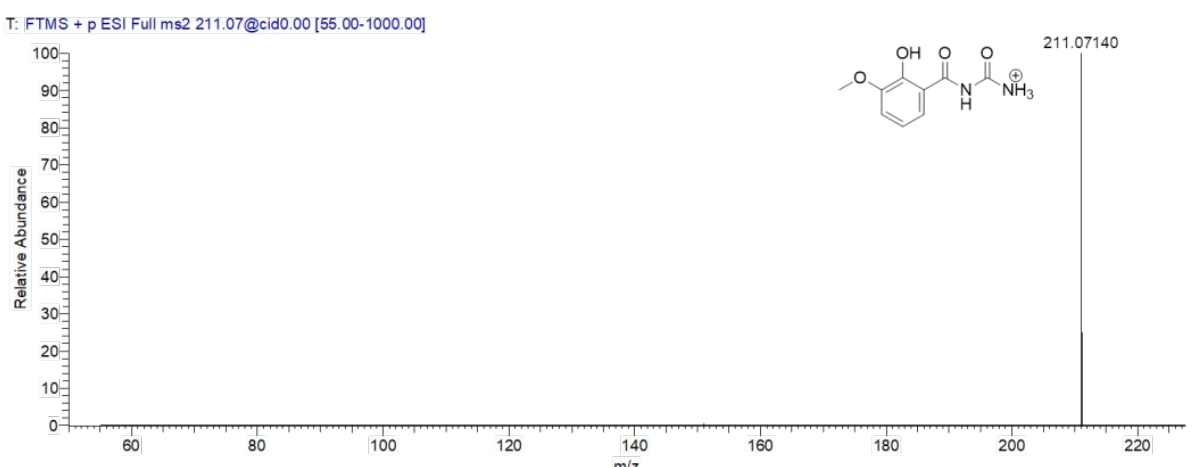

B

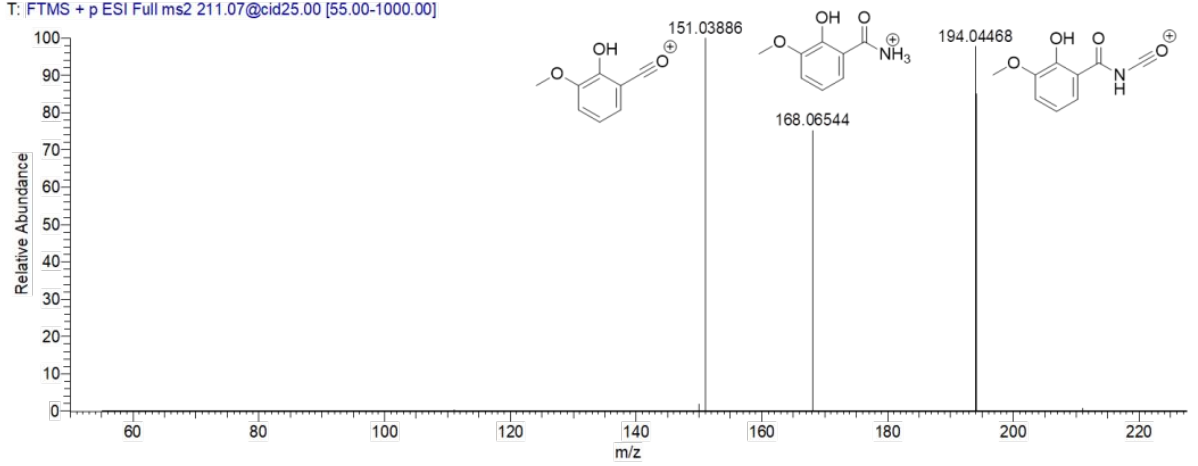

C T: FTMS + p ESI Full ms3 211.07@cid25.00 194.04@cid25.00 [50.00-1000.00]

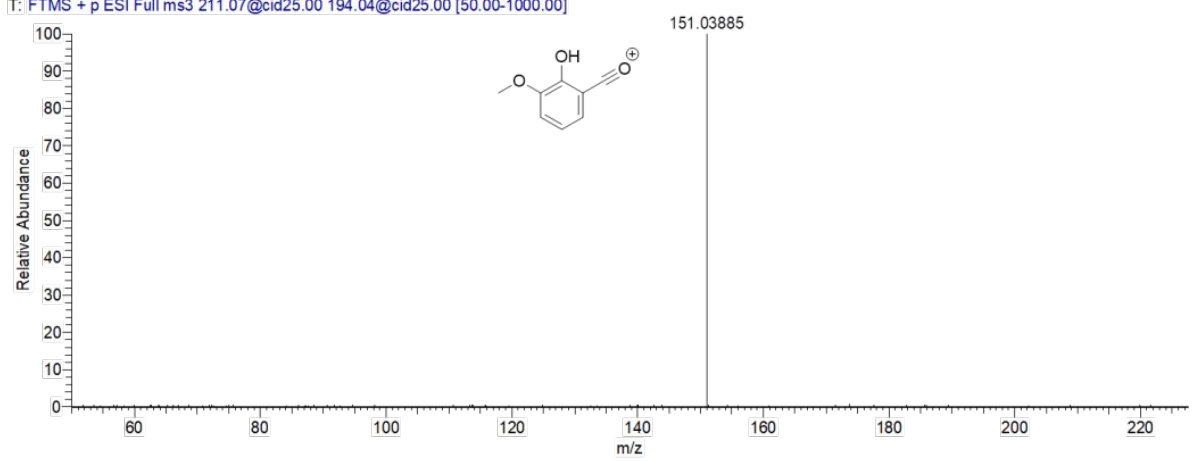

D T: FTMS + p ESI Full ms3 211.07@cid25.00 168.06@cid25.00 [50.00-1000.00]

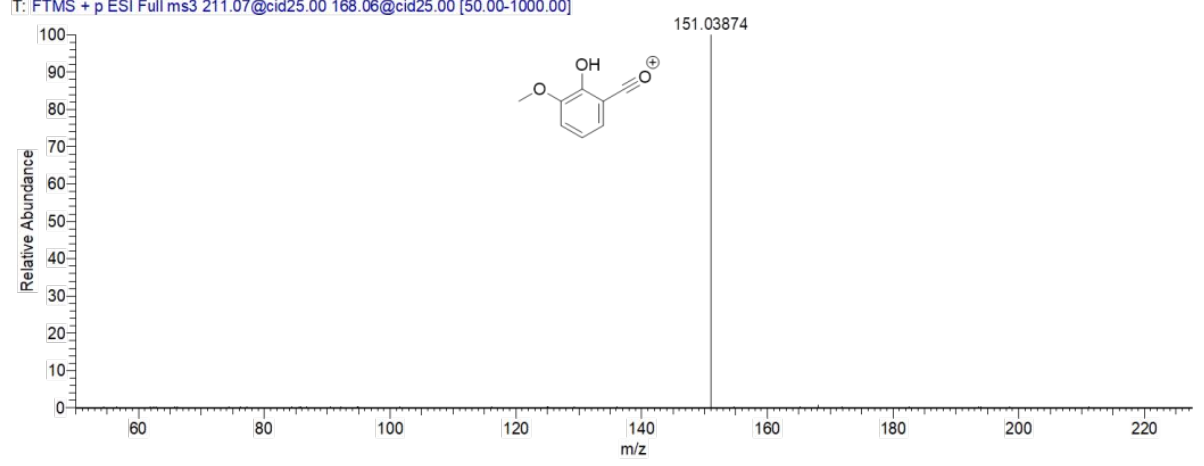

Figure S13. Tandem mass spectra of 1. (A) selection of the ion with $m / z 211.0714$ in $\mathrm{MS}^{2}$; (B) fragmentation of the ion with $\mathrm{m} / \mathrm{z} 211.0714$ in $\mathrm{MS}^{2}$; (C) fragmentation of the ion with $\mathrm{m} / \mathrm{z}$ 194.04468 in $\mathrm{MS}^{3}$; (D) fragmentation of the ion with $m / z 168.06544$ in $\mathrm{MS}^{3}$. 


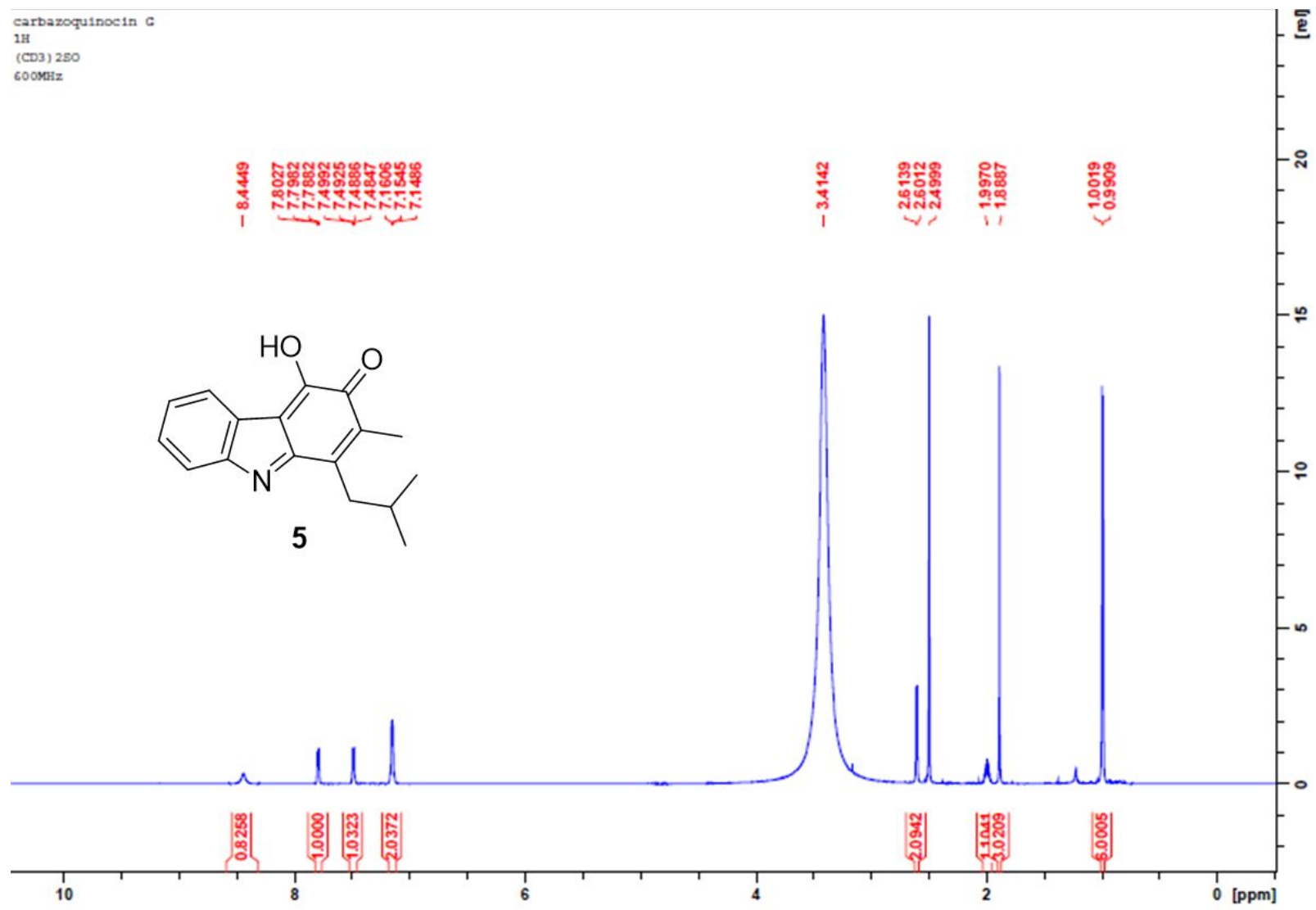

Figure S14. ${ }^{1} \mathrm{H}$ NMR $(600 \mathrm{MHz})$ data of 5, 98\% purity (DMSO- $\left.d_{6}\right)$. 


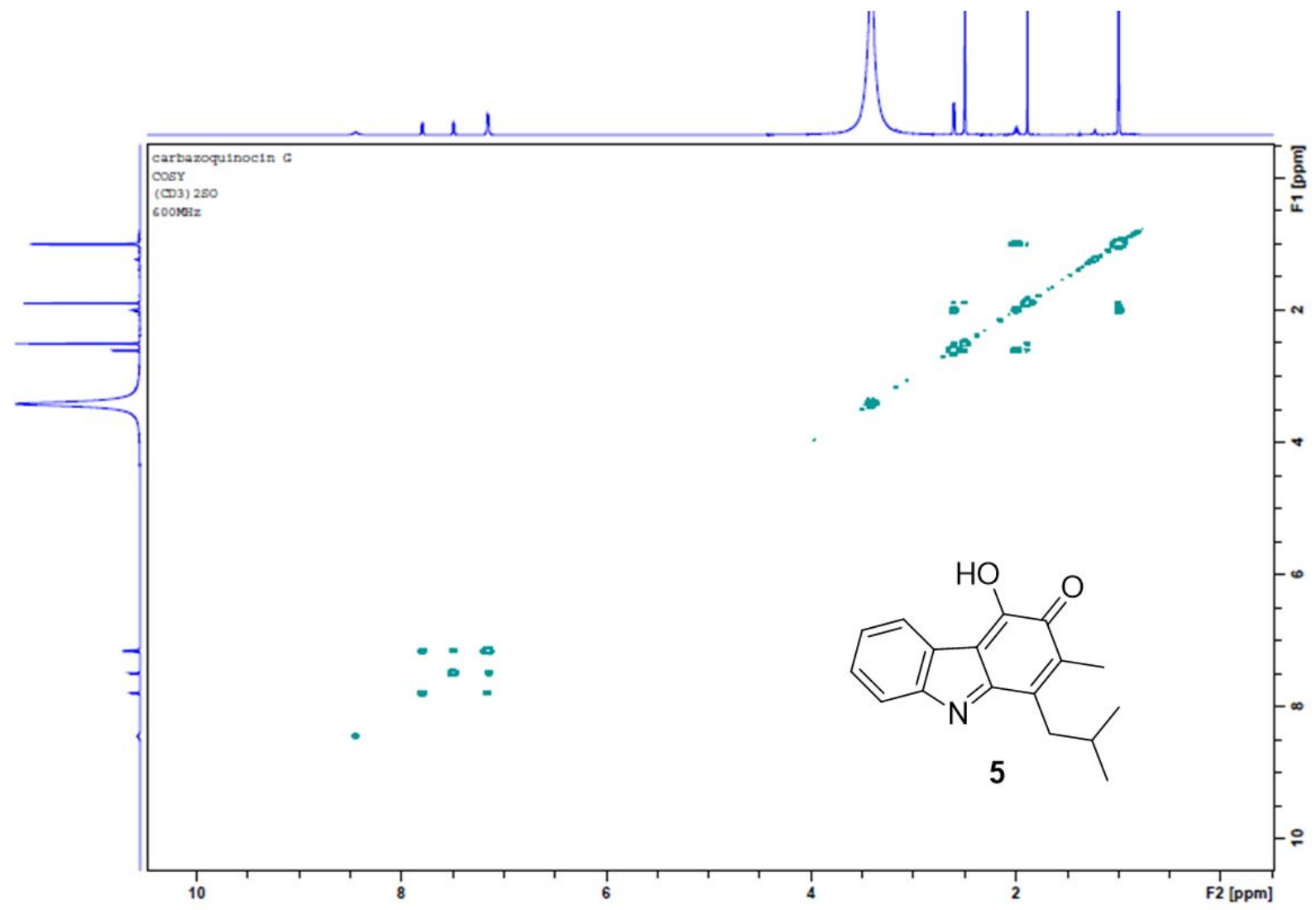

Figure S15. COSY NMR (600 MHz) data of $5\left(\mathrm{DMSO}-d_{6}\right)$. 


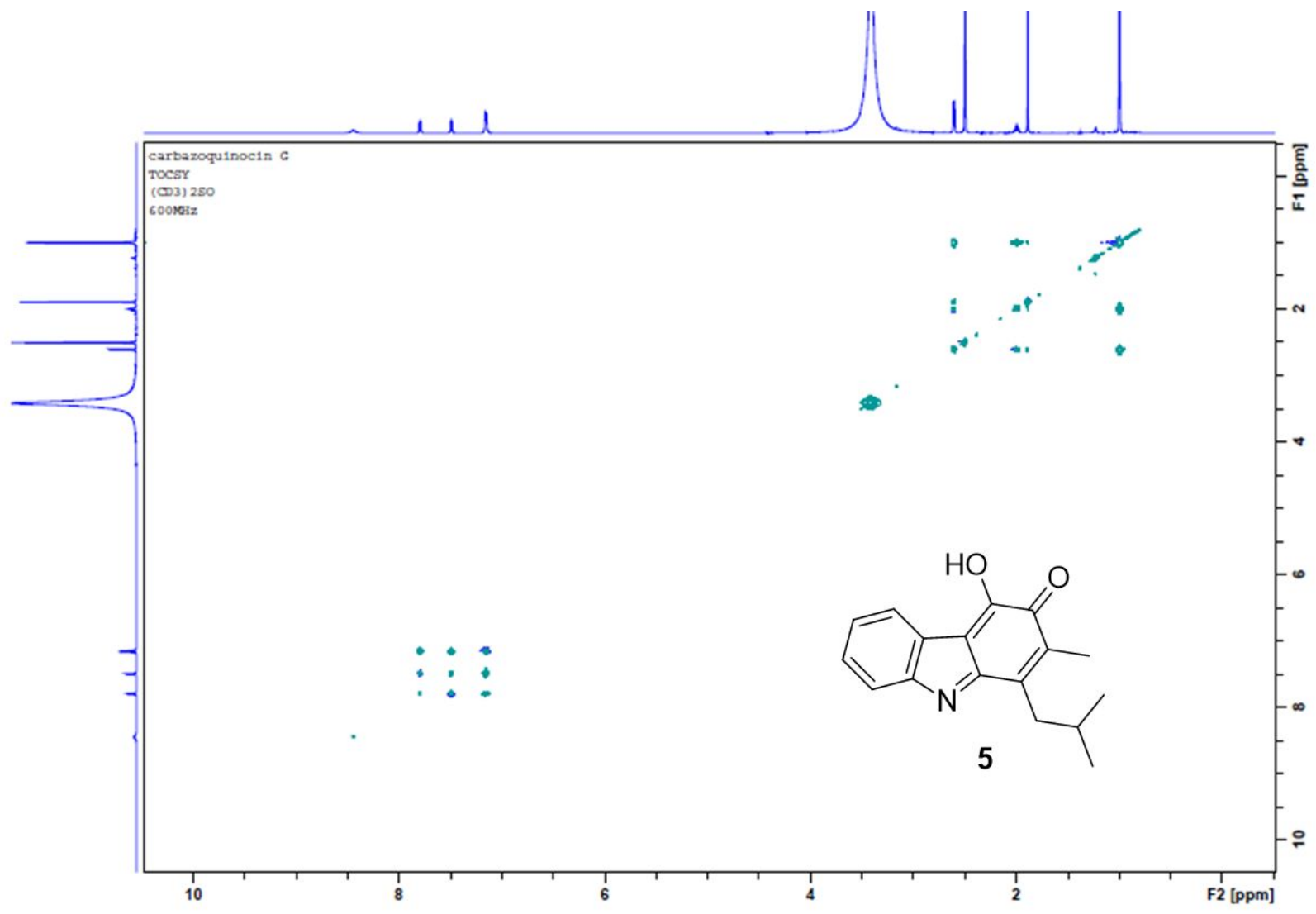

Figure S16. TOCSY NMR (600 MHz) data of 5 (DMSO- $\left.d_{6}\right)$. 


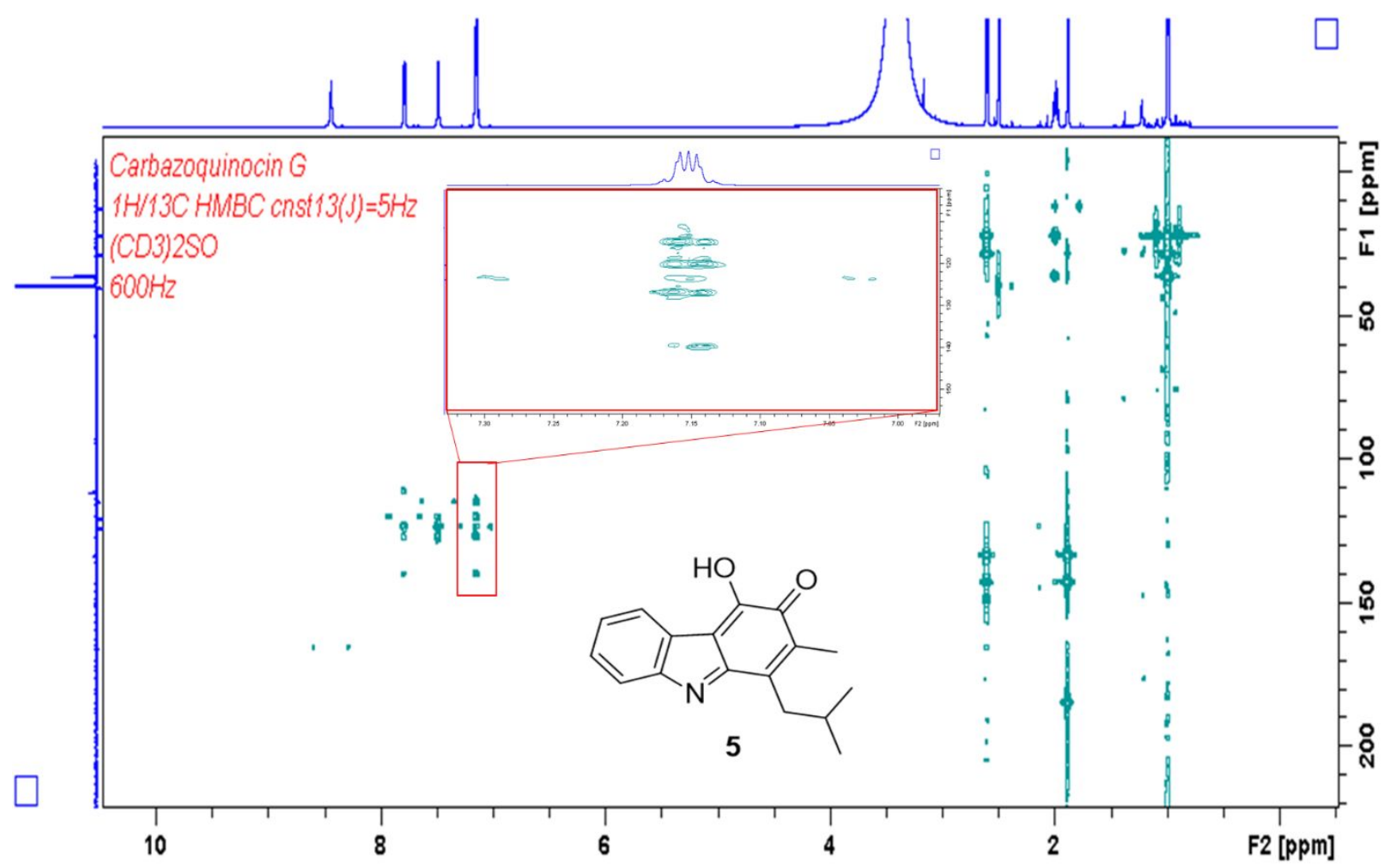

Figure S17. ${ }^{1} \mathrm{H}-{ }^{13} \mathrm{C}$ HMBC NMR $(600 \mathrm{MHz} / 125 \mathrm{MHz})$ data of 5, CNST13(J) = $5 \mathrm{~Hz}$ (DMSO$d_{6}$ ). 


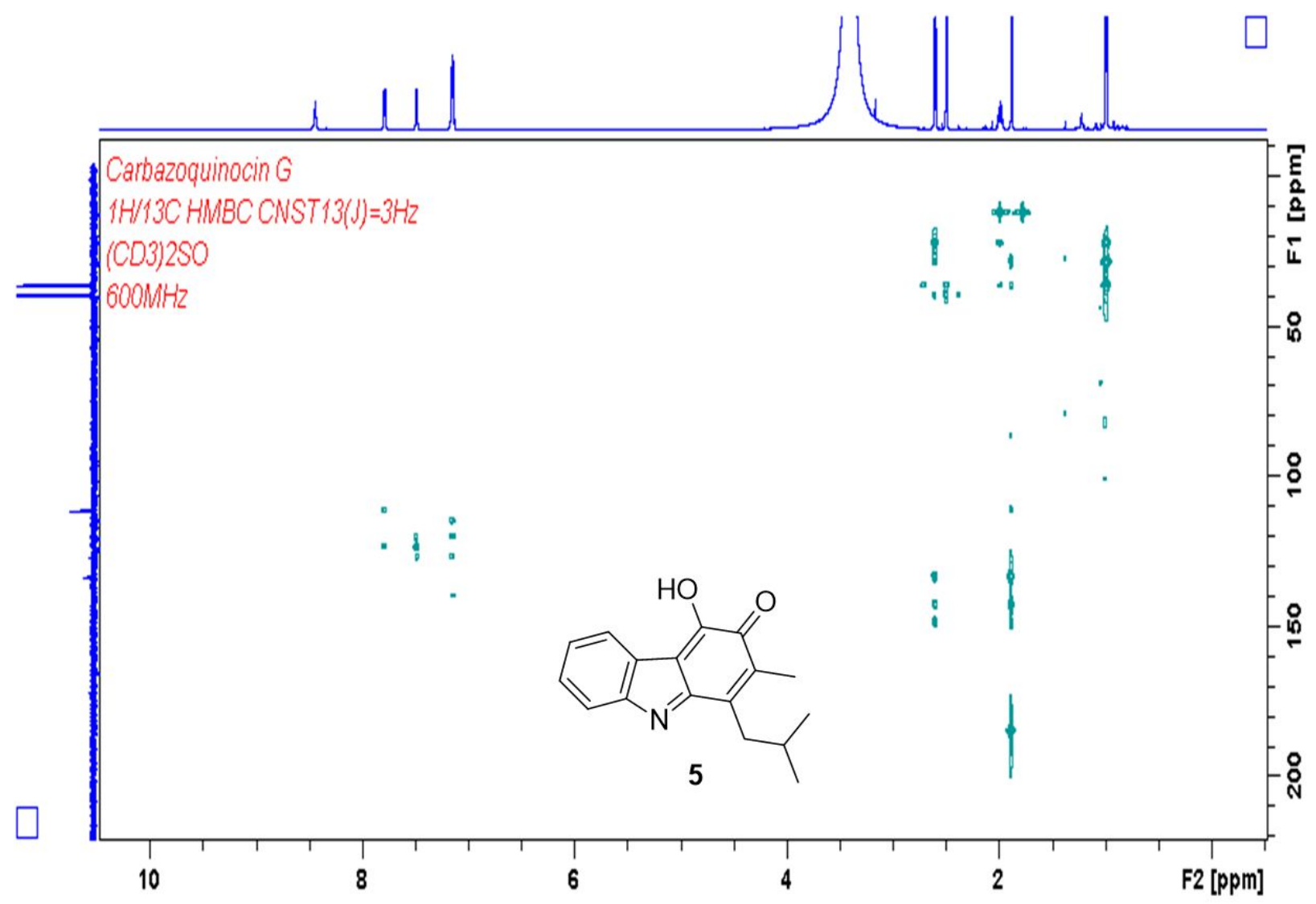

Figure S18. ${ }^{1} \mathrm{H}-{ }^{13} \mathrm{C}$ HMBC NMR (600 MHz / $\left.125 \mathrm{MHz}\right)$ data of 5, CNST13(J) = $3 \mathrm{~Hz}$ (DMSO$d_{6}$ ). 


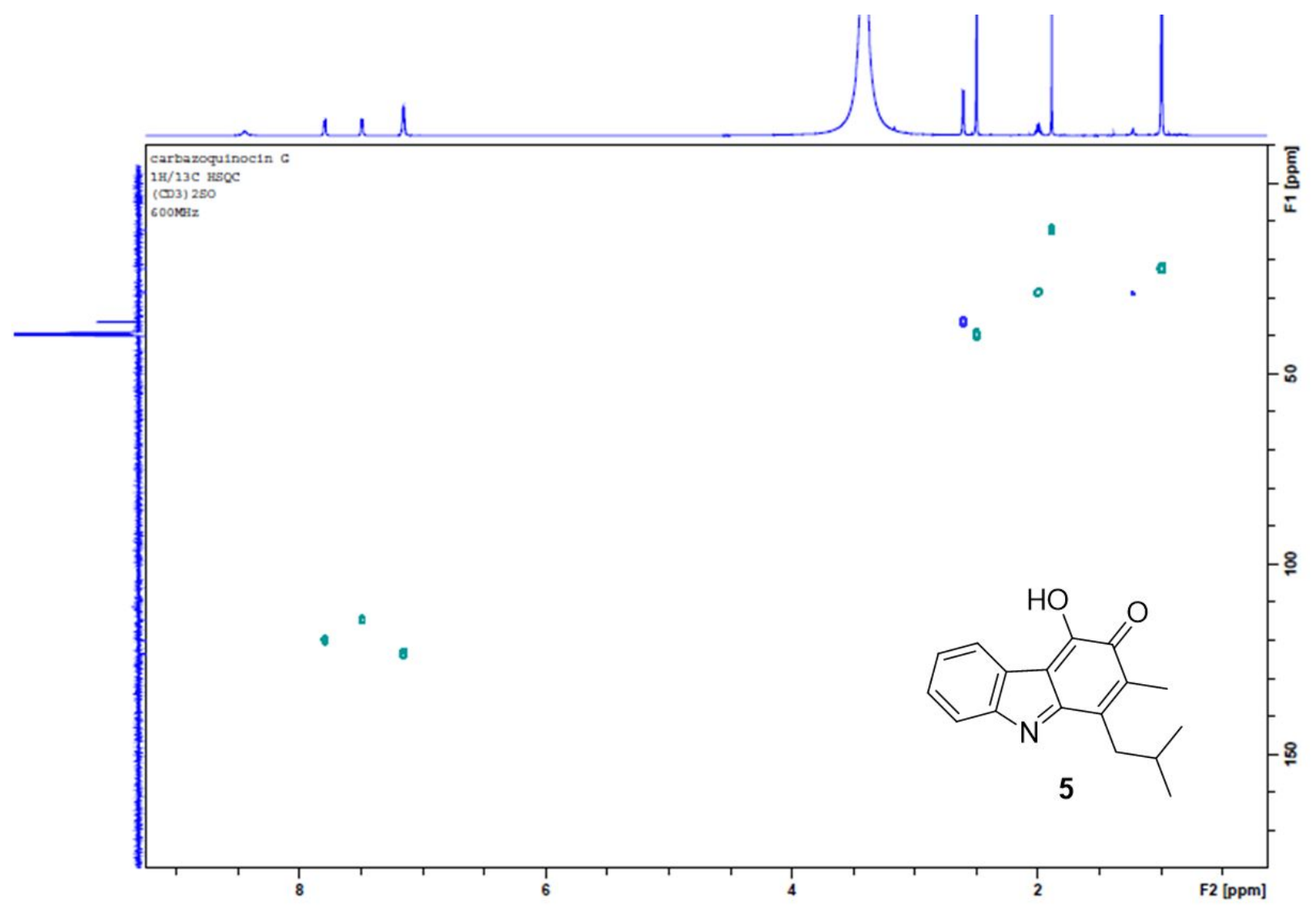

Figure S19. ${ }^{1} \mathrm{H}-{ }^{13} \mathrm{C}$ HSQC NMR $(600 \mathrm{MHz} / 125 \mathrm{MHz})$ data of 5 (DMSO- $\left.d_{6}\right)$. 


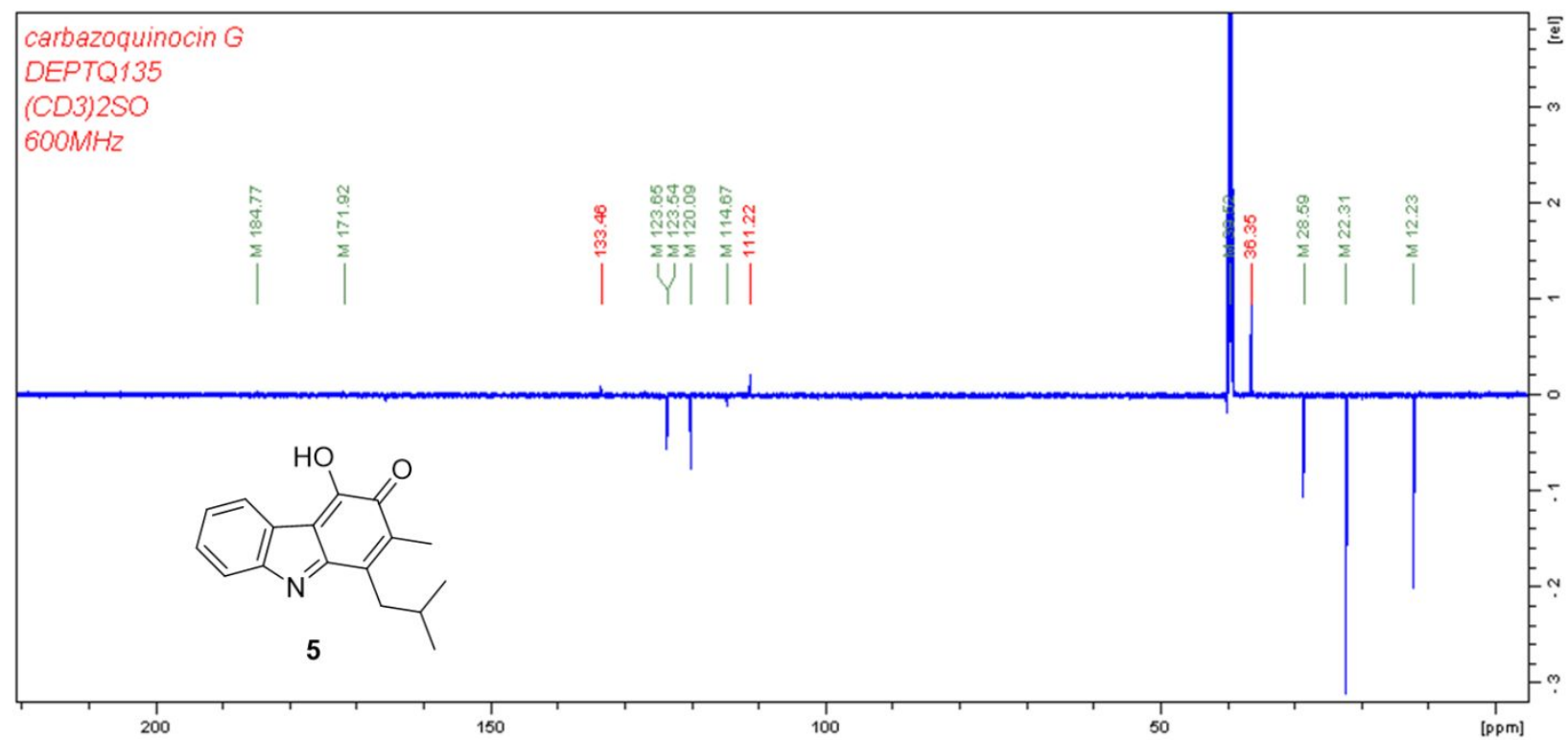

Figure S20. ${ }^{13} \mathrm{C}$ DEPTQ135 NMR $(125 \mathrm{MHz})$ data of 5 (DMSO- $\left.d_{6}\right)$. 


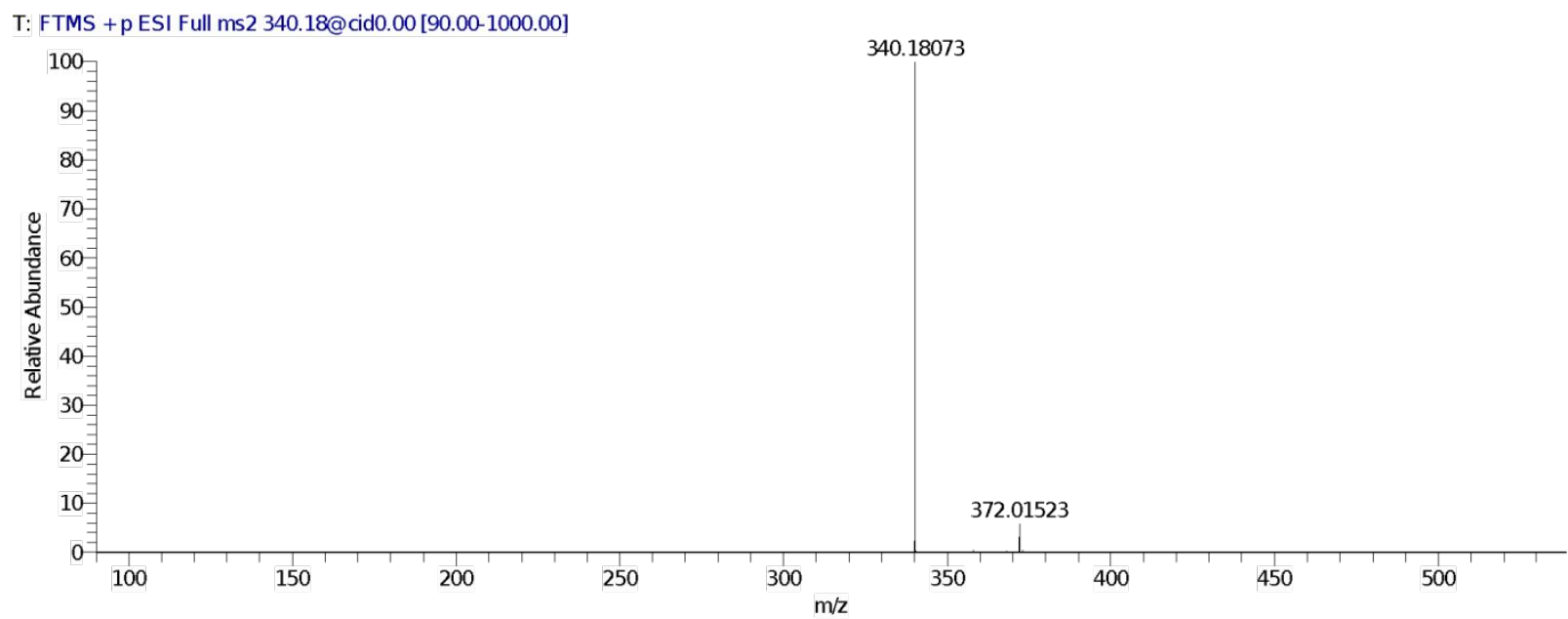

Figure S21. HRMS analysis of reaction product $7\left(\mathrm{C}_{23} \mathrm{H}_{22} \mathrm{~N}_{3}\right.$, calcd 340.1808). Compound 5 in $\mathrm{MeOH}$ containing $0.1 \%$ formic acid was first injected into the HRMS via direct infusion and the ion $\mathrm{m} / \mathrm{z} 340.1807$ was absent under an ESI-positive mode. The compound 5 sample was then added with $o$-phenylenediamine in $\mathrm{MeOH}$ containing $0.1 \%$ formic acid at a $1: 1$ ratio and the mixture was subjected to direct infusion to HRMS where the ion $m / z 340.1807$ was observed. 


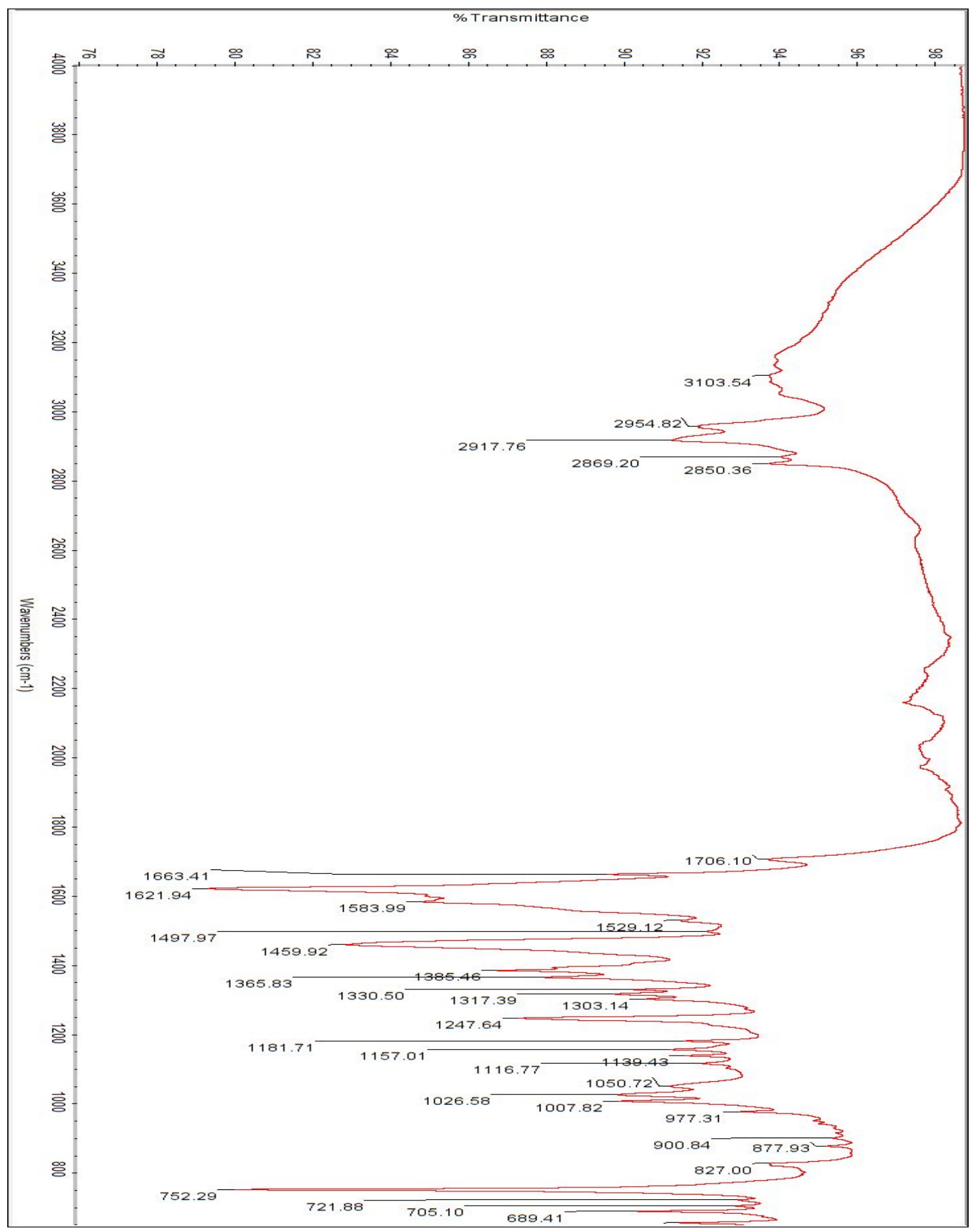

Figure S22. FTIR spectrum of compound 5. 